\title{
Violent and non-violent crime against adults with severe mental illness
}

H. Khalifeh, S. Johnson, L. M. Howard, R. Borschmann, D. Osborn, K. Dean, C. Hart, J. Hogg and P. Moran

\section{Background}

Little is known about the relative extent of crime against people with severe mental illness (SMI).

\section{Aims}

To assess the prevalence and impact of crime among people with SMI compared with the general population.

\section{Method}

A total of 361 psychiatric patients were interviewed using the national crime survey questionnaire, and findings compared with those from 3138 general population controls

participating in the contemporaneous national crime survey.

\section{Results}

Past-year crime was experienced by $40 \%$ of patients $v .14 \%$ of controls (adjusted odds ratio $(\mathrm{OR})=2.8,95 \% \mathrm{Cl} 2.0-3.8$ ); and violent assaults by $19 \%$ of patients $v$. $3 \%$ of controls (adjusted $\mathrm{OR}=5.3,95 \% \mathrm{Cl} 3.1-8.8$ ). Women with $\mathrm{SMl}$ had four-, ten- and four-fold increases in the odds of experiencing domestic, community and sexual violence, respectively. Victims with SMI were more likely to report psychosocial morbidity following violence than victims from the general population.

\section{Conclusions}

People with SMI are at greatly increased risk of crime and associated morbidity. Violence prevention policies should be particularly focused on people with SMI.

\section{Declaration of interest}

None.
Violence experienced by people with severe mental illness (SMI) is associated with poor symptomatic and functional recovery, high rates of comorbid post-traumatic stress disorder and poor treatment adherence. ${ }^{1-4}$ Violence prevention is a current public health priority $^{5,6}$ but little is known about whether violence against people with SMI differs substantially (in terms of nature, impact and reporting of crime) from violence against the general population. In order to address this gap in knowledge, we conducted a detailed comparative study of the prevalence and impact of violent and non-violent crime among people with SMI. Our primary hypothesis was that, compared with members of the general population, people with SMI would be at increased risk of being victims of personal and household crime, after taking into account sociodemographic confounders. Secondary hypotheses were that (a) the elevated risk of violent victimisation would be accounted for by social deprivation, substance misuse and violence perpetration, (b) victims with SMI would be more likely to experience adverse psychological and social sequelae than victims without SMI, and (c) victims with SMI would be less likely to report victimisation to professionals than victims without SMI.

\section{Method}

\section{Design}

In this cross-sectional study, we recruited people with SMI under the care of mental health services and interviewed them using a modified version of the Crime Survey for England and Wales (CSEW) questionnaire. We compared findings from our patient sample with findings from participants in the contemporaneous Office for National Statistics (ONS) crime victimisation survey (the CSEW); a nationally representative survey of adults living in private residential household in England and Wales. ${ }^{7}$

\section{Setting and participants}

Patients with SMI (the patient group) were recruited from two NHS mental health trusts, South London \& Maudsley and
Camden \& Islington, that cover a large diverse catchment area of 1.5 million people living in one of six London boroughs. In this study, SMI is defined in terms of chronicity and need for intensive care from secondary mental healthcare services, and includes people with psychotic disorders (such as schizophrenia or bipolar disorder), as well as those with other diagnoses (for example depression or personality disorder) of a severity requiring intensive service contact. This is in accordance with UK Department of Health definitions. ${ }^{8}$ Using central information technology registers, we identified all patients in receipt of ongoing care by a named keyworker in 19 community teams in these trusts, and selected a simple random sample for participation. Inclusion criteria for the patient sample were (a) age $18-65$, (b) under the care of community mental health teams in one of six London boroughs (Camden, Islington, Southwark, Lambeth, Croydon, Lewisham) for 1 year or more, and (c) living in the community. The exclusion criteria were (a) poor English language proficiency, (b) lacking capacity to consent (and not recovering this capacity over the study course), and (c) unavailable to participate (for example abroad, in prison). As stipulated by the ethics committee, patients were not approached directly but were recruited via their care coordinators. We summarised the study to care coordinators and provided them with patient information sheets. We checked with them the eligibility of patients from our random list who were on their caseload. Care coordinators gave eligible patients a patient information sheet and asked their permission for a researcher to contact them. Patients who granted permission were contacted by a researcher, who answered any queries they had about the study and sought their written consent to participate in the study. Those who provided written consent were interviewed at a time and place that suited them.

The ONS survey recruited a nationally representative random sample of people living in private residential households in England and Wales (the control group). ${ }^{7}$ The inclusion criteria for the comparison sample were (a) participants in the 2011/ 2012 CSEW, (b) resident in any of London's 32 boroughs, and 
(c) aged 18-65. We excluded controls with self-reported chronic, disabling mental illness. This study was approved by the Kent Local Research Ethics Committee. Written informed consent was obtained from all patients who participated in the study.

\section{Interview procedures}

The ONS national crime survey was conducted by lay interviewers in participants' homes. ${ }^{9}$ It comprised (a) a face-to-face interview, which focused on being a victim of personal or household crime in the past year, and (b) an opt-in self-completion questionnaire for those aged 18-59, which focused on the more sensitive topics of domestic violence, sexual violence, substance misuse and violence perpetration. The self-completion module is typically taken up by $70 \%$ of eligible respondents. ${ }^{9}$

We modified the ONS survey questionnaire for use with our patient population, mainly by omitting optional modules outside the scope of our research question. The patient survey was conducted by one of six interviewers (three psychologists, one psychiatrist and two research assistants) in either a clinical setting $(86 \%)$ or in the participant's home $(14 \%)$, depending on participant choice. One interviewer from each site attended ONS CSEW interviewer training and instructed the others, in order to keep interview procedures as similar to the ONS survey as possible.

\section{Measures}

The primary exposure was SMI (as defined by the patient inclusion criteria above; namely chronic mental disorder requiring ongoing secondary mental healthcare). The primary outcome was being a victim of violent or non-violent crime in the past year among those aged $18-65$, as disclosed in the face-to-face interview. Following CSEW definitions, 'crime' referred to experiences disclosed by participants, whether or not they were reported to the police. Personal crime was defined as (a) any physical or sexual assault, (b) personal acquisitive crime (robbery, attempted robbery, theft from the person, theft of personal belongings). Household crime was defined as (a) criminal damage, (b) household acquisitive crime (burglary or attempted burglary, theft from household).

The key secondary outcome was being a victim of any physical or sexual violence in the past year among those aged $18-59$, as disclosed in either the face-to-face interview or self-completion module. This included domestic violence (perpetrated by partners or family members) and community violence (perpetrated by strangers or acquaintances).

The following additional outcomes of interest were limited to people who reported being victims of violence in the face-to-face interviews: (a) impact of violent crime, measured by asking victims whether they had reported one or more of the following as a result of victimisation: depression, anxiety or panic attacks; loss of confidence; relationship breakdowns; financial loss; time off work; physical illness; injury, (b) reporting of violent crime to the police and satisfaction with police response, (c) among the patient group, reporting to mental health professionals and unmet needs.

Potential confounders, identified a priori from the literature, were: age, gender, ethnicity, marital status, living alone, employment, housing tenure, small area multiple deprivation index (MDI; a composite measure of deprivation in administratively defined areas of around 1500 residents) and output area characteristics (OAC, whereby areas are classified by census-derived sociodemographic characteristics). Potential explanatory factors were substance misuse and violence perpetration. The National Crime Survey has four modules that are each asked of a random quarter of the sample in order to decrease interviewee burden, and the violence perpetration questions were included in one of these modules, so data on this measure were only available for a random quarter of general population participants.

For the patient group, we obtained clinical information from clinical records and/or care coordinators where patients consented to this. Clinical diagnosis was defined as the primary ICD-10 diagnosis ${ }^{10}$ given in the clinical records.

\section{Statistical analysis}

We used Hsieh's methods to estimate sample size (a widely used method for estimating sample sizes for logistic regression). ${ }^{11}$ To detect a three-fold excess risk of any victimisation among patients (at the $5 \%$ significance level, with a power of $80 \%$ ), we estimated that we needed 270 patients and 1080 controls.

To address our primary hypothesis, we used multivariate logistic regression to estimate odds ratios for crime victimisation in those with and without SMI, adjusting for the potential confounders listed above (see Table 3 for details of covariates). We tested for a gender interaction in the association between SMI and victimisation. To address our secondary hypothesis on violence victimisation, we estimated the odds for this outcome stratified by gender. We entered covariates in three sequential blocks for demographics, social deprivation and substance misuse/violence perpetration, to explore to what extent these domains accounted for any excess victimisation risk (see Tables 4 and 5 for details on covariates). To address our secondary hypotheses on impact and disclosure, we estimated the relative odds of these outcomes among violence victims with and without SMI, adjusting for victim and crime characteristics (see Table 6 for details).

We conducted a sensitivity analysis estimating the adjusted odds for victimisation among patients and a comparison subgroup matched on borough of residence (restricted to controls who lived in the six London boroughs from which patients were recruited) (online Table DS1). We also conducted a subgroup analysis by diagnosis, comparing patients with schizophrenia and those with other diagnoses $v$. the control group (online Table DS2). Where there were missing data on more than $5 \%$ for a secondary outcome, we described the distribution of missing data across the patient and control groups, and carried out sensitivity analyses to explore potential bias.

\section{Results}

\section{Sample flow and characteristics}

We recruited patients from 19 community mental health teams. Of 1099 patients randomly selected from the care programme approach (CPA) registers for these teams, 697 (63\%) were eligible for this study, of whom $361(52 \%)$ completed the survey from September 2011 to March 2013 (Fig. 1). For the control group we used data from the CSEW conducted from April 2011 to April 2012 (the most recently available CSEW data), with a response rate of $68 \%$ for London residents. ${ }^{7}$ Of the 3224 CSEW participants aged 18-65 living in London, 3138 met our control inclusion criteria, after excluding 86 participants $(2.7 \%)$ who reported disabling mental illness. Data on domestic violence from selfcompletion modules was available for $85 \%(292 / 345)$ of the patient group and 74\% (2092/2812) of the control group aged $18-59$.

The sample sociodemographics are shown in Table 1. People with SMI had greater levels of social deprivation than the comparison group. The clinical characteristics of the patient group are shown in Table 2. Around $60 \%$ had a diagnosis of 
(a)

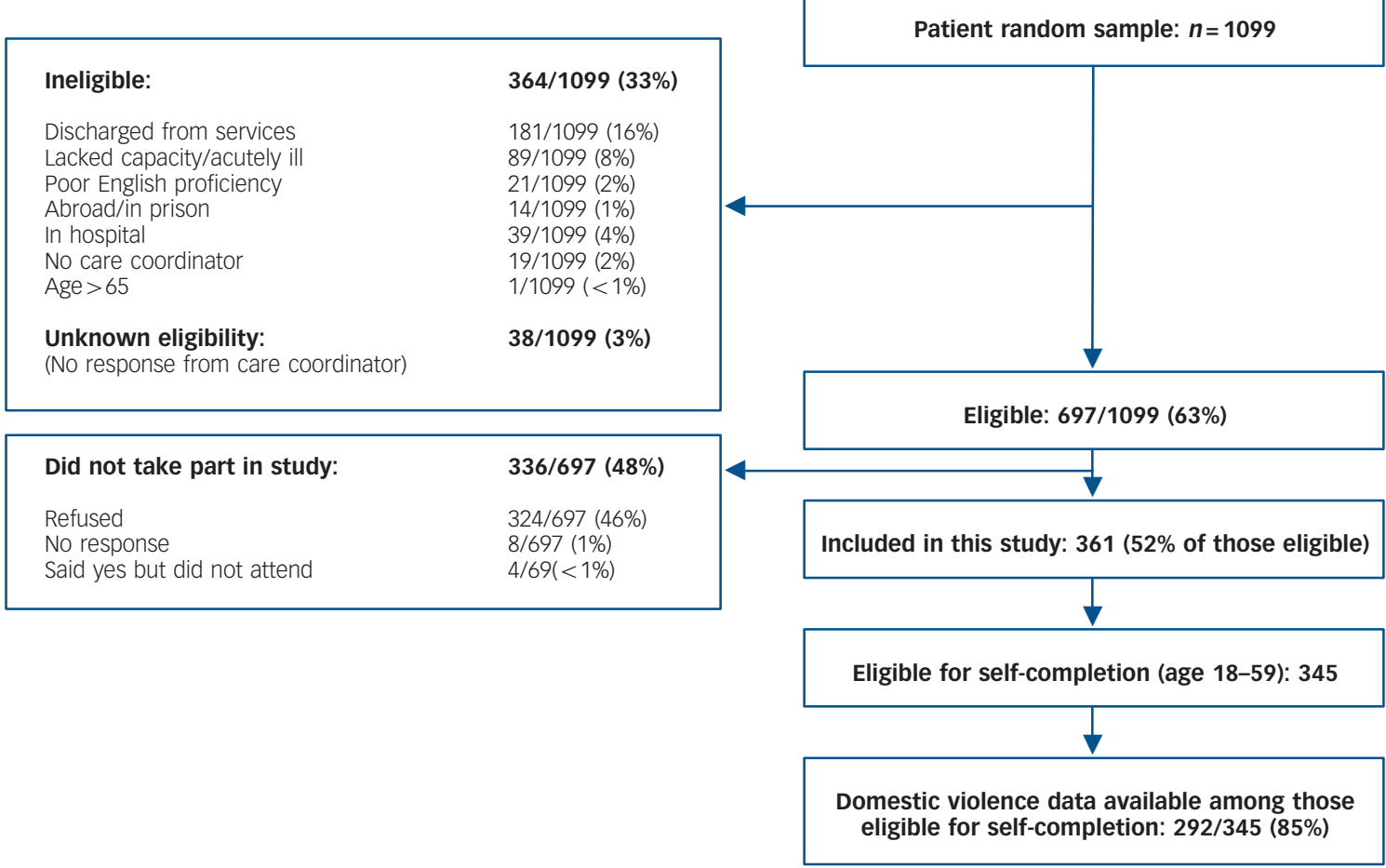

(b)

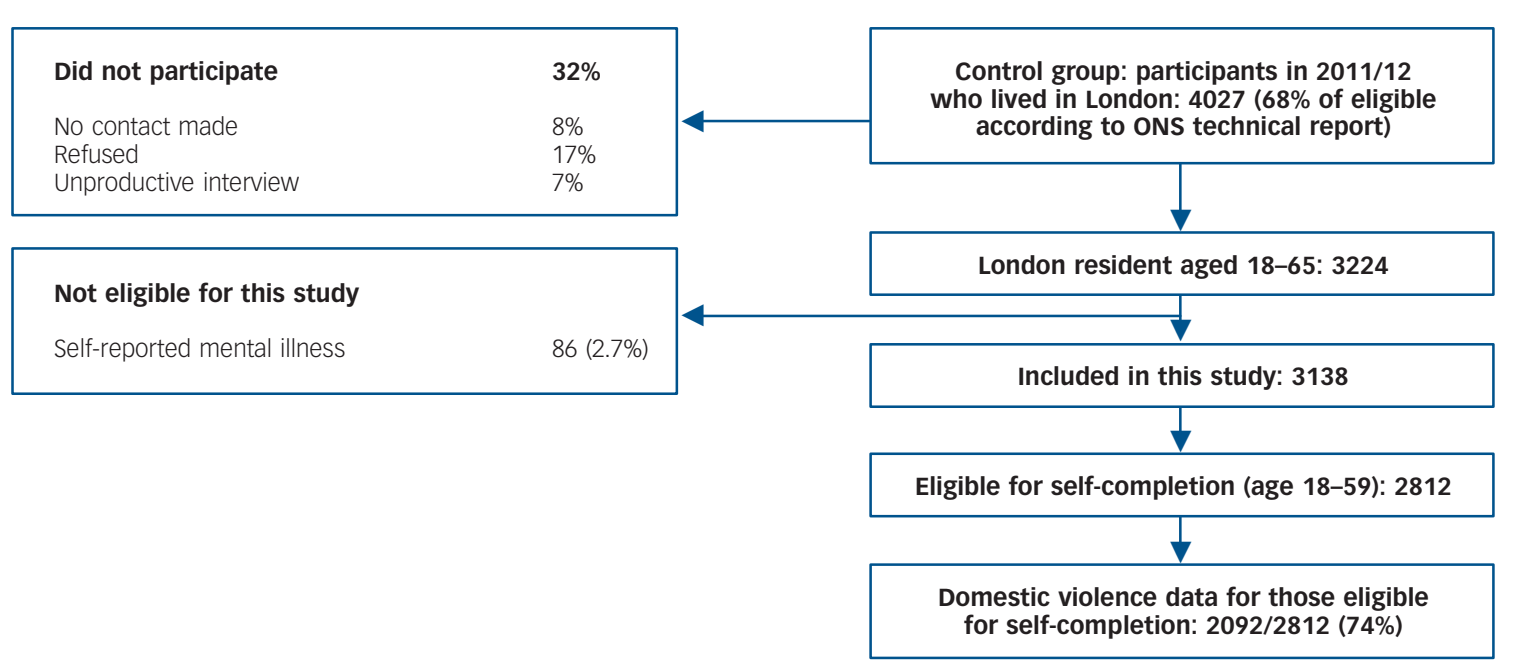

Fig. 1 Flow of participants in (a) the patient group and (b) the control group.

ONS, Office for National Statistics.

schizophrenia and $51 \%$ had a history of admission under the Mental Health Act.

\section{Crime victimisation: face-to-face interview measures}

Table 3 shows the prevalence and odds ratios for victimisation experiences reported in the face-to-face interview (adjusted for sociodemographics). The experience of being a victim of any crime was more prevalent among the patient than the control group ( $40 \%$ v. $14 \%$, respectively; adjusted odds ratio $(\mathrm{OR})=2.8$, $95 \%$ CI $2.0-3.8$ ). In total, $26 \%$ of the patient group $v .7 \%$ of the control group were victims of any personal crime (adjusted $\mathrm{OR}=3.0,95 \% \mathrm{CI} 2.1-4.4)$ and $23 \%$ v. $9 \%$ were victims of any household crime (adjusted OR=2.9, 95\% CI 2.1-4.0). Those in the patient group were at increased adjusted odds of being a victim of assault (adjusted OR $=5.3,95 \%$ CI 3.1-8.8), household acquisitive crime (adjusted $\mathrm{OR}=2.7,95 \%$ CI 1.9-3.8) and criminal damage (adjusted OR $=3.4,95 \%$ CI 1.8-6.3); but not of personal acquisitive crime (adjusted $\mathrm{OR}=1.4,95 \%$ CI $0.83-2.4$ ). There was an interaction by gender for assault, where adjusted odds ratios for women with SMI compared with control women was 12.0 (95\% CI 5.4-26.5), and adjusted odds ratios for men with SMI compared with control men was 3.0 (95\% CI 1.5-6.0, $P$ for interaction 0.02).

The results of the sensitivity analysis, which compared the patient and control groups residing in the same boroughs, are reported in online Table DS1 and broadly reflect the findings above. The subgroups analyses, which compared general population controls with (a) people with schizophrenia and (b) those with other diagnoses, show somewhat lower relative odds for those with schizophrenia, but confidence intervals were overlapping for most outcomes (online Table DS2). 


\begin{tabular}{|c|c|c|}
\hline Characteristic $^{\mathrm{a}}$ & $\begin{array}{l}\text { Patient group } \\
\quad(n=361)\end{array}$ & $\begin{array}{l}\text { Control group } \\
\qquad(n=3138)\end{array}$ \\
\hline Age, mean (s.d.) & $41.8(0.57)$ & $40.9(0.22)$ \\
\hline \multicolumn{3}{|l|}{ Gender, \% (n) } \\
\hline Male & $56.2(203)$ & $46.0(1445)$ \\
\hline Female & $43.8(158)$ & $54.0(1693)$ \\
\hline \multicolumn{3}{|l|}{ Ethnicity, \% (n) } \\
\hline White & $41.6(150)$ & 63.4 (1991) \\
\hline Asian/Chinese/other & $35.2(127)$ & $23.0(721)$ \\
\hline Black/Black British & $23.0(83)$ & $13.4(419)$ \\
\hline \multicolumn{3}{|l|}{ Marital status, \% (n) } \\
\hline Single & $72.6(262)$ & $43.1(1353)$ \\
\hline Married/cohabiting & $7.8(28)$ & $42.6(1337)$ \\
\hline Divorced/separated/widowed & $18.3(66)$ & $14.2(447)$ \\
\hline \multicolumn{3}{|l|}{ Educational achievement, \% (n) } \\
\hline High & $27.1(98)$ & $52.0(1633)$ \\
\hline Low-medium & $52.6(190)$ & $35.6(1116)$ \\
\hline None & $19.9(72)$ & $12.3(385)$ \\
\hline \multicolumn{3}{|l|}{ Employment status, \% (n) } \\
\hline Employed & $10.2(37)$ & 71.3 (2238) \\
\hline Student/economically inactive & $10.5(38)$ & $19.1(599)$ \\
\hline Sick/unemployed & $79.2(286)$ & $9.3(293)$ \\
\hline \multicolumn{3}{|l|}{ Tenancy, \% (n) } \\
\hline Owners & $6.1(22)$ & 48.9 (1534) \\
\hline Private renters & 30.7 (111) & $30.2(948)$ \\
\hline Council renters & $62.9(227)$ & $20.7(648)$ \\
\hline \multicolumn{3}{|l|}{$\begin{array}{l}\text { Area multiple deprivation index } \\
\text { quintiles, \% (n) }\end{array}$} \\
\hline Quintile 1: 20\% least deprived & $0.3(1)$ & $8.7(273)$ \\
\hline Quintile 2 & $1.1(4)$ & $13.6(428)$ \\
\hline Quintile 3 & $8.9(32)$ & $20.5(643)$ \\
\hline Quintile 4 & $36.3(131)$ & $30.2(948)$ \\
\hline Quintile 5: 20\% most deprived & $52.4(189)$ & $27.0(846)$ \\
\hline \multicolumn{3}{|l|}{ Output area classification, \% (n) } \\
\hline Multicultural & $84.5(305)$ & $58.1(1824)$ \\
\hline
\end{tabular}

\section{Physical and sexual assaults: face-to-face interview and self-completion measures}

Table 4 shows the prevalence and odds ratios for assaults reported in either the face-to-face interview or self-completion module, by gender. The prevalence of any past-year physical or sexual violence in the patient $v$. control group was $27 \% v$. 5\% for women and $23 \%$ v. $5 \%$ for men. The odds for any violence victimisation, adjusted
Table 2 Clinical characteristics of patient group (obtained from clinical records or care coordinator)

\begin{tabular}{|lc|}
\hline Clinical characteristic & $\begin{array}{c}\text { Patient group, \% }(n) \\
(n=361)\end{array}$ \\
\hline $\begin{array}{l}\text { Diagnosis } \\
\text { Schizophrenia and related disorders }\end{array}$ & $58.4(211)$ \\
Bipolar affective disorder & $12.5(45)$ \\
Depression \& other mood disorders & $9.7(35)$ \\
Personality disorders & $8.0(29)$ \\
Other & $9.1(33)$ \\
Missing & $2.2(8)$ \\
\hline Illness onset more than 10 years ago & $47.4(171)$ \\
\hline History of admission under Mental Health Act & $51.2(185)$ \\
\hline More than 5 admissions & $12.5(45)$ \\
\hline a. 'Other' diagnoses included: neurotic and stress-related disorders $(n=8)$; organic \\
mental disorders, intellectual disability/disorders of psychological development $(n=8)$, \\
mental disorders as a result of substance misuse $(n=9)$, unspecified mental disorder \\
$(n=8)$.
\end{tabular}

for sociodemographics and substance misuse, were 6.4 (95\% CI 3.1-13.1) among women and 2.7 (95\% CI 1.2-5.8) among men. Women with SMI were at increased adjusted odds of all subtypes of violent victimisation; including domestic physical violence $(\mathrm{OR}=3.5,95 \%$ CI 1.3-9.7), community physical violence $(\mathrm{OR}=10.3,95 \%$ CI $3.4-31.7)$ and sexual violence $(\mathrm{OR}=3.7$, 95\% CI 1.1-11.8). Men were at increased risk of being a victim of domestic physical violence (OR $=3.9,95 \%$ CI 1.03-15.2), but their risk of community physical violence was not elevated at the $5 \%$ significance level $(\mathrm{OR}=2.2,95 \% \mathrm{CI} 0.9-5.3)$. The absolute number of men reporting sexual violence was too small to allow for stable estimates.

The effect of adjusting for different risk factors on the association between SMI and violence victimisation is shown in Table 5. Adjustment for social deprivation resulted in little change in the magnitude of this association, whereas additional adjustment for substance misuse and violence perpetration led to a sizeable reduction. After taking into account sociodemographics, substance misuse and violence perpetration, the adjusted odds of violence victimisation was 1.9 (95\% CI 0.53-6.8) among men and 7.7 (95\% CI 2.5-23.7) among women. Therefore, these factors accounted for the excess risk among men but not among women with SMI.

\section{Impact, reporting and unmet needs among victims of violent crime}

A quarter to half of victims in the patient group reported adverse psychosocial effects as a result of victimisation, and $80 \%$ reported

Table 3 Prevalence and odds ratios of past-year personal and household crime victimisation in patients and controls

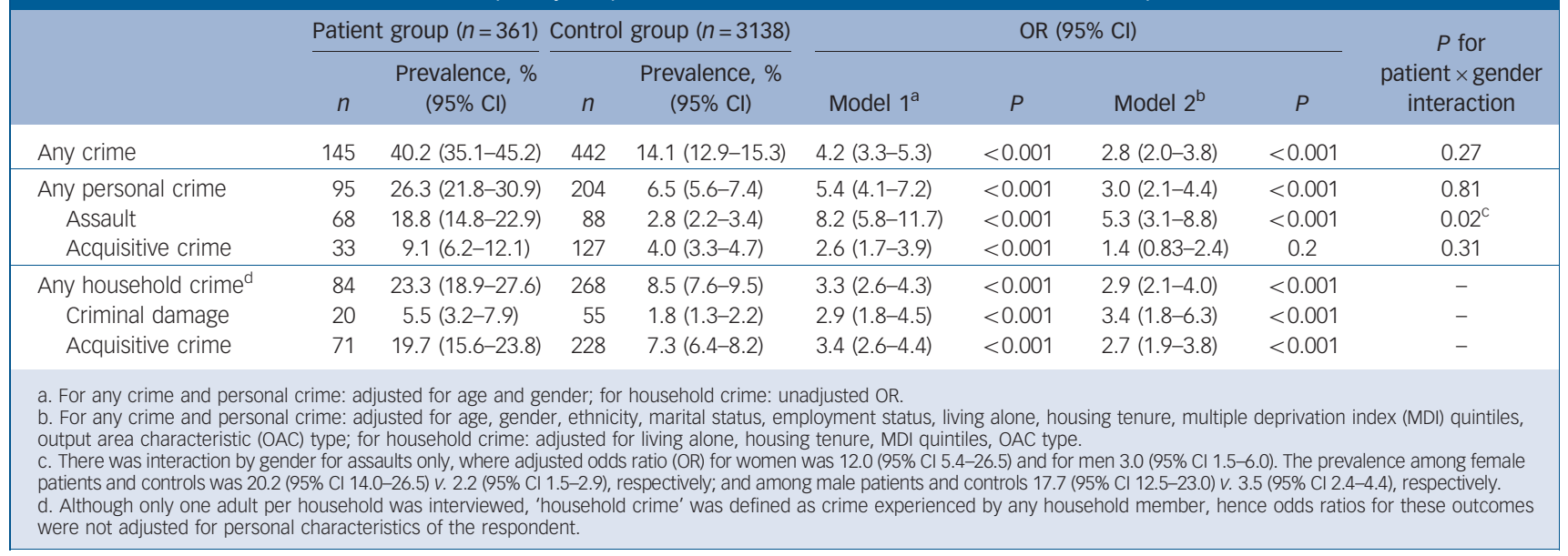


Table 4 Prevalence and odds ratios of past-year violence victimisation among the patient and control groups, by gender

\begin{tabular}{|c|c|c|c|c|c|c|c|c|}
\hline & \multicolumn{2}{|c|}{ Patient group } & \multicolumn{2}{|c|}{ Control group } & \multicolumn{4}{|c|}{ OR $(95 \% \mathrm{Cl})$} \\
\hline & $n$ & $\begin{array}{l}\text { Prevalence, } \\
\%(95 \% \mathrm{Cl})\end{array}$ & $n$ & $\begin{array}{l}\text { Prevalence, } \\
\%(95 \% \mathrm{Cl})\end{array}$ & $\begin{array}{l}\text { OR, adjusted for } \\
\text { age and gender }\end{array}$ & $P$ & $\begin{array}{c}\text { OR, } \\
\text { full adjusted }\end{array}$ & $P$ \\
\hline \multicolumn{9}{|l|}{ Women } \\
\hline Any assault & $35 / 128$ & $27.3(19.6-35.1)$ & $60 / 1114$ & $5.4(4.1-6.7)$ & $8.7(5.2-14.4)$ & $<0.001$ & $6.4(3.1-13.1)$ & $<0.001$ \\
\hline Physical assault & $30 / 128$ & $23.4(16.1-30.8)$ & $39 / 1114$ & $3.5(2.4-4.6)$ & $11.2(6.3-19.7)$ & $<0.001$ & $6.3(2.9-13.7)$ & $<0.001$ \\
\hline Sexual assault & $12 / 128$ & $9.4(4.3-14.4)$ & $26 / 1114$ & $2.3(1.4-3.2)$ & $4.6(2.1-10.0)$ & $<0.001$ & $3.7(1.1-11.8)$ & 0.03 \\
\hline Domestic assault ${ }^{\mathrm{b}}$ & $15 / 128$ & $11.7(6.1-17.3)$ & 20/1114 & $1.8(1.0-2.6)$ & $8.3(3.9-17.7)$ & $<0.001$ & $3.5(1.3-9.7)$ & 0.01 \\
\hline Community assault $^{c}$ & $16 / 128$ & $12.5(6.7-18.2)$ & 20/1114 & $1.8(1.0-2.5)$ & $10.8(5.3-22.1)$ & $<0.001$ & $10.3(3.4-31.7)$ & $<0.001$ \\
\hline \multicolumn{9}{|l|}{ Men } \\
\hline Any assault & $38 / 164$ & $23.2(16.7-29.6)$ & $53 / 978$ & $5.4(4.0-6.8)$ & $5.6(3.4-9.1)$ & $<0.001$ & $2.7(1.2-5.8)$ & 0.01 \\
\hline Physical assault & $37 / 164$ & $22.6(16.1-29.0)$ & $52 / 978$ & $5.3(3.9-6.7)$ & $5.4(3.3-8.9)$ & $<0.001$ & $2.5(1.2-5.6)$ & 0.02 \\
\hline Sexual assault ${ }^{d}$ & - & - & - & - & - & - & - & - \\
\hline Domestic assault ${ }^{\mathrm{b}}$ & $11 / 164$ & $6.7(2.8-10.5)$ & $18 / 978$ & $1.8(1.0-2.7)$ & $4.6(2.1-10.1)$ & $<0.001$ & $3.9(1.03-15.2)$ & 0.04 \\
\hline Community assault $^{\mathrm{C}}$ & $28 / 164$ & $17.1(11.3-22.9)$ & $32 / 978$ & $3.3(2.2-4.4)$ & $6.2(3.5-11.2)$ & $<0.001$ & $2.2(0.9-5.3)$ & 0.08 \\
\hline
\end{tabular}

Table 5 Exploring risk factors for excess odds of violence victimisation among patients

\begin{tabular}{|c|c|c|c|c|c|c|c|c|}
\hline & \multirow{2}{*}{$\begin{array}{c}\text { Patient } \\
\text { group, } n / N\end{array}$} & \multirow{2}{*}{$\begin{array}{l}\text { Control } \\
\text { group, } n / N\end{array}$} & \multicolumn{6}{|c|}{ OR $(95 \% \mathrm{Cl})$ of violence victimisation in patient $v$. control group } \\
\hline & & & Model $1^{\mathrm{a}}$ & $P$ & Model $2^{b}$ & $P$ & Model $3^{c}$ & $P$ \\
\hline Women & $32 / 110$ & $15 / 277$ & $9.1(4.5-18.4)$ & $<0.001$ & $11.7(4.1-33.3)$ & $<0.001$ & $7.7(2.5-23.7)$ & $<0.001$ \\
\hline Men & $32 / 142$ & $14 / 248$ & $5.7(2.8-11.4)$ & $<0.001$ & $4.9(1.4-15.2)$ & 0.01 & $1.9(0.53-6.8)$ & 0.32 \\
\hline
\end{tabular}

physical injury (Table 6). Victims in the patient group were more likely to report that violence led to social problems, adverse psychological effects (depression, anxiety or panic attacks) and injury than victims in the control group; with four- to five-fold higher odds for the latter two after adjusting for victim and crime characteristics. There was no difference in the proportion reporting financial loss or physical ill health following violence experiences.

Victimisation was reported to the police for $58 \%$ of victims in the patient group and $49 \%$ of victims in the control group $(P=0.72)$, with no difference in reporting, even after adjusting for victim and crime characteristics. Patients were more dissatisfied with the police response $(50 \% v .24 \%, P=0.02)$, but this difference was no longer statistically significant at the $5 \%$ level after adjusting for victim/crime characteristics. The same conclusions were reached following a sensitivity analysis; conducted to explore non-response bias, since there was unequal missing data between patients and controls on these outcomes (Table 6). Among the patient group who were victims of violence, $68 \%$ reported their experiences to a mental health professional. A total of $55 \%$ had unmet support needs; with around a third reporting an unmet need for 'talking help', help with the Criminal Justice System process or practical/financial support.

\begin{tabular}{|c|c|c|c|c|c|c|c|}
\hline & \multirow[b]{2}{*}{$\begin{array}{l}\text { Patient group, } \\
n / N(\%)\end{array}$} & \multirow[b]{2}{*}{$\begin{array}{c}\text { Control group, } \\
n / N(\%)\end{array}$} & \multirow[b]{2}{*}{$P$} & \multicolumn{4}{|c|}{ OR $(95 \% \mathrm{Cl})$} \\
\hline & & & & Adjusted $\mathrm{OR}^{\mathrm{a}}$ & $P$ & $\begin{array}{l}\text { Adjusted OR from } \\
\text { sensitivity analysis }\end{array}$ & $P$ \\
\hline \multicolumn{8}{|l|}{ Impact } \\
\hline Anxiety/depression/panic attacks & $27 / 53(50.9)$ & $17 / 87(19.5)$ & $<0.001$ & $5.1(1.9-13.7)$ & $<0.01$ & $3.4(1.4-8.6)$ & $<0.01$ \\
\hline Confidence loss /social withdrawal & $32 / 53(60.4)$ & 33/87 (37.9) & 0.01 & $2.2(1.0-5.3)$ & 0.06 & $1.4(0.66-3.2)$ & 0.35 \\
\hline Financial loss & $13 / 52(25.0)$ & $14 / 87(16.1)$ & 0.2 & $1.3(0.43-3.8)$ & 0.65 & $0.95(0.33-2.7)$ & 0.92 \\
\hline Physical health problems & $19 / 51(37.3)$ & $25 / 87(28.7)$ & 0.3 & $0.87(0.36-2.1)$ & 0.76 & $0.68(0.28-1.6)$ & 0.39 \\
\hline Injury (for assault victims) & $45 / 56(80.4)$ & $35 / 73(47.9)$ & $<0.001$ & $4.4(1.7-11.3)$ & $<0.01$ & $3.9(1.7-9.1)$ & $<0.01$ \\
\hline \multicolumn{8}{|l|}{ Reporting } \\
\hline Reported to police & $37 / 64(57.8)$ & $43 / 88(48.9)$ & 0.27 & $1.0(0.48-2.3)$ & 0.92 & $0.93(0.43-2.0)$ & 0.85 \\
\hline Dissatisfied with police response & $14 / 28(50.0)$ & $10 / 42(23.8)$ & 0.02 & $2.7(0.63-11.8)$ & 0.18 & $1.9(0.42-6.7)$ & 0.46 \\
\hline Reported to mental health professional & $42 / 62(67.7)$ & - & - & - & - & - & - \\
\hline \multicolumn{8}{|l|}{ Help wanted (but not received) } \\
\hline Any help & 28/51 (54.9) & - & - & & & & \\
\hline Talking help & $12 / 43(27.9)$ & - & - & & & & \\
\hline Help with Criminal Justice System process & $11 / 41(26.8)$ & - & - & & & & \\
\hline Financial/practical help & 14/44 (31.8) & - & - & & & & \\
\hline
\end{tabular}




\section{Discussion}

\section{Main findings}

This study compared the prevalence and correlates of violent and non-violent crime victimisation among people with SMI with a general population control group, and compared impact and disclosure of victimisation. In total, $40 \%$ of the patient group compared with $14 \%$ of the control group were victims of a crime in the preceding year. Our primary hypothesis that patients would be at increased odds of personal and household crime compared with the general population controls was supported; those in the patient group were five times more likely to be victims of assault, and three times more likely to be victims of household acquisitive crime and criminal damage, after adjusting for sociodemographics and area characteristics. Women with SMI were at particularly high risk of violence, both community and domestic. Our secondary hypothesis that social deprivation, substance misuse and violence perpetration would account for any excess risk of violence victimisation among patients was supported among men with SMI but not among women with SMI (who had eight-fold adjusted odds). Our secondary hypotheses on impact and reporting of crime were partially supported: crime led to greater reported psychological adversity and injury by the victims in the patient group than those in the control group, but surprisingly patients and controls were equally likely to report victimisation to the police.

\section{Findings in the context of past studies}

Previously published studies on violence victimisation among people with SMI have had highly heterogeneous settings, populations and measures and have reported prevalence estimates ranging from $4 \%$ to $58 \% .^{12-16}$ Few studies have compared victimisation among mental health service users with a control group. ${ }^{17-21}$ Silver in the USA compared discharged psychiatric patients with a neighbourhood control sample, and found a two-fold increase in violence victimisation after adjusting for sociodemographics and violence perpetration. ${ }^{19}$ Teplin et al in the USA and Sturup et al in Sweden compared violent crime against psychiatric patients with data from participants in national crime surveys and after adjusting for a very limited number of confounders found 12-fold and 6-fold higher risk among patients, respectively. ${ }^{18,21}$ Finally, a New Zealand birth cohort found that violent victimisation among a small number of people with schizophreniform disorder $(n=38)$ was three-fold higher than among those without any psychiatric disorder. ${ }^{20}$ The studies adjusted for a limited number of confounders and did not assess the impact or reporting of violence. Some past studies measured and reported on victimisation by any perpetrators, including partners and family members, ${ }^{18}$ but this is one of the few studies to report separately on domestic violence (perpetrated by partners and family members) and community violence (perpetrated by strangers or acquaintances). This is important, since these forms of violence have distinct interventions. ${ }^{22}$ We found greatly elevated odds of victimisation compared with our general population control group for all violence types (physical and sexual; domestic and community), even after adjusting for a broader range of key individual, household and area characteristics than in studies carried out previously. ${ }^{18-21}$

Our finding that women with SMI were particularly vulnerable to violence is consistent with evidence from Sweden and the USA. ${ }^{18,21,23}$ In the general population, violence prevention among women is focused on domestic and sexual violence, ${ }^{24,25}$ but our finding that women with SMI had increased risks for both domestic and community violence suggests the need for broader interventions in this group.

We found that people with SMI are more likely to report adverse psychological and social effects once victimised. This would compound the personal, public health and economic costs of victimisation in this group, especially given the relatively large contribution of psychosocial impact to the overall economic cost of crime. ${ }^{26}$ These findings suggest that people with SMI should be prioritised in public health policies on violence prevention directed at vulnerable groups. Although SMI is uncommon, affecting around $3 \%$ of the population, ${ }^{27}$ it is one of the leading causes of global disease burden; and this study and others suggest that experiencing violence is associated with worse function and quality of life among this group. ${ }^{28}$

Past studies have shown that substance misuse, social isolation, homelessness and violence perpetration are important risk factors for victimisation among people with SMI; ${ }^{13,29,30}$ whereas treatment adherence was protective. ${ }^{31}$ In our study, substance misuse and violence perpetration accounted for the excess risk of victimisation among men but not among women; suggesting the need for gender-sensitive interventions given the likely differences in risk pathways.

In routine clinical practice, victimisation is underdetected by mental health professionals, and where it is detected, concerns may not be promptly acted upon. ${ }^{32}$ Half of the violence victims in our study had unmet support needs. Mental health professionals need to identify victimisation, mitigate modifiable risk factors and address comorbidity.

Surprisingly, patients were as likely to report victimisation to the police and to progress through the Criminal Justice System as the general population, contradicting previous qualitative evidence that suggested people with mental health problems had limited access to the judicial system. ${ }^{33}$ Nonetheless, those in the patient group were less likely to be satisfied with the response of the police, with qualitative research conducted by the UK Charity Victim Support suggesting that they are often not believed and discriminated against within the Criminal Justice System. ${ }^{34}$ Clearly criminal justice policies must protect against such discrimination. Half of patients had unmet support needs, including for practical/financial help, psychological support and help with the Criminal Justice System process.

\section{Strengths and limitations}

Strengths of this study include a large sample size, with a comparison group drawn from the same geographical area. We derived detailed information on the nature, impact and reporting of crime, and used self-reported measures for domestic and sexual violence (which have higher disclosure rates than interview measures). ${ }^{35}$ The response rate was somewhat low at $52 \%$. However, the study researched a sensitive topic, in a population which may have additional barriers to participating in such a study. Although domestic and sexual violence are sensitive topics for any group, they may be even more sensitive and complex for patients with SMI in secondary mental healthcare to discuss, since patients may worry about additional consequences of disclosure such as involuntary hospital admission. ${ }^{34}$ We used a rigorous random sampling procedure, using a complete list of all patients on the caseload of included teams, whether or not they were actively engaged in treatment. As stipulated by the ethics committee, we recruited indirectly via care coordinators rather than through direct contact with patients. These factors may explain the lower response rate in this study compared with those using a convenience sample $\mathrm{e}^{17,36}$ or direct recruitment of patients attending out-patient or in-patient services. ${ }^{18}$ Non-responders 
had the same demographic profile (in terms of age and gender) as participants. We did not have additional details on the characteristics of non-responders, so it is difficult to comment on the likely magnitude and direction of non-response bias. We speculate that some patients may have failed to respond because they had experienced or were experiencing violence and were worried about the consequences of disclosure (for example increased violence or coercive treatment), which would have led to an underestimate of violence prevalence. Others may have failed to respond because they did not have past experiences of violence and so did not perceive this study as relevant to them, which would have led to an overestimate of violence experiences. The overall effect is difficult to ascertain, but the odds ratios are sizeable and unlikely to be fully explained by non-response bias.

The findings have external validity, mirroring those of related studies in the USA and Sweden. ${ }^{18,21}$ There is potential for observer bias (since interviewers in the patient survey were not masked to the main hypothesis) and reporting bias (the patient and control groups may have different thresholds for disclosing victimisation), but this is mitigated by the highly structured questionnaire, and there is evidence that self-reported victimisation among people with SMI is valid and reliable. ${ }^{18,37,38}$ There may be a reporting bias for domestic violence because of the different interview settings the controls were interviewed at home but most patients were interviewed in clinic, and disclosure may be easier in a clinical setting (although all home-based interviews were conducted in a private setting without others present, and participants themselves filled out a computer-based questionnaire in confidence).

Another limitation is the different sociodemographic profile of the patient and control groups, but we carefully adjusted for a broad range of individual and household measures. Our sensitivity analysis found no evidence for confounding by area of residence. Bias from missing data on impact is possible, but there was no evidence for this from our sensitivity analysis. A small proportion of the control group may have an SMI, since we used a self-reported measure to exclude mental illness in this group. However, the prevalence of SMI in the general population is less than $3 \%,{ }^{27}$ and the presence of people with SMI in the control group would have led us to underestimate the relative odds. Findings on prevalence are likely to generalise to other Western urban settings with similar background levels of violence, and those on the relative risk of victimisation are likely to generalise to settings where people with SMI have a similar sociodemographic and clinical profile to the one described here.

In conclusion, victimisation among people with SMI is more prevalent and associated with greater psychosocial morbidity than victimisation among the general population. Our research has shown that women with SMI are at particularly high risk of both domestic and community violence. Violence prevention for people with SMI is likely to require an integrated response by mental health professionals, third-sector organisations and the Criminal Justice System.

H. Khalifeh, MSC, MRCPsych, s. Johnson, MD, MRCPsych, Division of Psychiatry, University College London, London; L. M. Howard, PhD, MRCPsych, R. Borschmann, DClinPsy, David Goldberg Centre, Institute of Psychiatry, London; D. Osborn, PhD, MRCPsych, Division of Psychiatry, University College London, London; K. Dean, PhD, MRCPsych, Institute of Psychiatry, London, and School of Psychiatry, K. Dean, PhD, MRCPsych, Institute of Psychiatry, London, and School of Psychiatry,
University of New South Wales and Justice Health \& Forensic Mental Health Network C. Hart, MSC, J. Hogg, MSC, P. Moran, PhD, MRCPsych, David Goldberg Centre, Institute of Psychiatry, London, UK

Correspondence: H. Khalifeh, Division of Psychiatry, University College London, Charles Bell House, 67-73 Riding House Street, London W1W 7EJ, UK. Email: h.khalifeh@ucl.ac.uk

First received 4 Mar 2014, final revision 8 Jul 2014, accepted 25 Sep 2014

\section{Funding}

H.K. was supported by and Medical Research Council (MRC) Population Health Sciences Fellowship (reference G0802432/1). P.M., J.H., C.H., R.B. and K.D. were supported by a Big Lottery grant (C247A1198). L.M.H. was supported by a National Institute for Health Research (NIHR) Research Professorship NHR-RP-R3-12-011. P.M. and LM. were also supported by the NIHR Mental Health Biomedical Research Centre at South London and Maudsley NHS Foundation Trust and King's College London. This study was funded by the MRC and the Big Lottery, the funders had no role in the study design; the collection analysis or interpretation of data; the writing of the report; or in the decision to submit the paper for publication. The researchers are independent from the funders and the sponsors.

\section{Acknowledgements}

We acknowledge the support of Camden \& Islington South London \& Maudsley NHS Foundation Trusts. We acknowledge the CSEW Principal Investigator (Office for National Statistics), sponsors (Home Office, Ministry of Justice, Office for National Statistics), data collectors (TNS BMRB) and the UK Data Archive. We thank Kirsty Collins and Megan Lawrence from the Mental Health Support Network for help with recruitment we are grateful to all the patients and healthcare professionals who took part in this study. The views expressed in this publication are those of the authors alone.

\section{References}

1 Goodman LA, Rosenberg SD, Mueser KT, Drake RE. Physical and sexual assault history in women with serious mental illness: prevalence, correlates, treatment, and future research directions. Schizophr Bull 1997; 23: 685-96.

2 Mueser KT, Rosenberg SD, Goodman LA, Trumbetta SL. Trauma, PTSD, and the course of severe mental illness: an interactive model. Schizophr Res 2002; 53: 123-43.

3 Neria Y, Bromet EJ, Carlson GA, Naz B. Assaultive trauma and illness course in psychotic bipolar disorder: findings from the suffolk county mental health project. Acta Psychiatr Scand 2005; 111: 380-3.

4 Hodgins S, Lincoln T, Mak T. Experiences of victimisation and depression are associated with community functioning among men with schizophrenia. Soc Psychiatry Psychiatr Epidemiol 2009; 44: 448-57.

5 World Health Organization. Responding to Intimate Partner and Sexual Violence against Women: WHO Clinical and Policy Guidelines. WHO, 2013.

6 Bellis MA, Hughes K, Perkins C, Bennet A. Protecting People, Promoting Health. A Public Health Approach to Violence Prevention for England. Centre for Public Health, 2012.

7 TNS-BMRB. The 2011/12 Crime Survey for England and Wales: Technical Report. TNS-BMRB, 2012.

8 Charlwood P, Mason A, Goldacre M, Cleary R, Wilkinson E. Health Outcome Indicators: Severe Mental IIIness. Report of a Working Group to the Department of Health. National Centre for Health Outcome Development, 1999.

9 Office for National Statistics. User Guide to Crime Statistics for England and Wales. HMSO, 2012.

10 World Health Organization. The ICD-10 Classification of Mental and Behavioural Disorders: Diagnostic Criteria for Research. WHO, 1993.

11 Hsieh FY. A simple method of sample size calculation for linear and logistic regression. Stat Med 1998; 17: 1623.

12 Maniglio R. Severe mental illness and criminal victimization: a systematic review. Acta Psychiatr Scand 2009; 119: 180-91

13 Dean $\mathrm{K}$, Moran P, Fahy T, Tyrer P, Leese M, Creed F, et al. Predictors of violent victimization amongst those with psychosis. Acta Psychiatr Scand 2007: 116: 345-53.

14 Hodgins S, Alderton J, Cree A, Aboud A, Mak T. Aggressive behaviour victimisation and crime among severely mentally ill patients requiring hospitalisation. Br J Psychiatry 2007; 191: 343-50.

15 Walsh E, Moran P, Scott C, McKenzie K, Burns T, Creed F, et al. Prevalence of violent victimisation in severe mental illness. Br J Psychiatry 2003; 183: 233-8.

16 Hiday VA, Swanson JW, Swartz MS, Borum R, Wagner HR, Hiday VA, et al. Victimization: a link between mental illness and violence? Int J Law Psychiatry 2001; 24: 559-72 (erratum in 25: 533-6).

17 Hughes K, Bellis MA, Jones L, Wood S, Bates G, Eckley L, et al. Prevalence and risk of violence against adults with disabilities: a systematic review and meta-analysis of observational studies. Lancet 2012; 379: 1621-9.

18 Teplin LA, McClelland GM, Abram KM, Weiner DA. Crime victimization in adults with severe mental illness - comparison with the national crime victimization survey. Arch Gen Psychiatry 2005; 62: 911-21. 
19 Silver E. Mental disorder and violent victimization: the mediating role of involvement in conflicted social relationships. Criminology 2002; 40 191-212.

20 Silver E, Arseneault L, Langley J, Caspi A, Moffitt TE. Mental disorder and violent victimization in a total birth cohort. Am J Public Health 2005; 95 : 2015-21.

21 Sturup J, Sorman K, Lindqvist $\mathrm{P}$, Kristiansson M. Violent victimisation of psychiatric patients: a Swedish case-control study. Soc Psychiatry Psychiatr Epidemiol 2011; 46: 29-34.

22 Krug EG. World Report on Violence and Health. World Health Organization, 2002

23 Khalifeh H, Dean K. Gender and violence against people with severe mental illness. Int Rev Psych 2010; 22: 535-46.

24 World Health Organization. Preventing Intimate Partner and Sexual Violence against Women: Taking Action and Generating Evidence. WHO, 2010.

25 National Institute for Health and Care Excellence. Domestic Violence and Abuse: How Health Services, Social Care and the Organisations they Work with can Respond Effectively. NICE, 2014.

26 Dubourg R, Hamed J. Estimates of the Economic and Social Costs of Crime in England and Wales: Costs of Crime against Individuals and Households, 2003/04. Home Office, 2005.

27 McManus S, Meltzer H, Brugha T, Bebbington P, Jenkins R. Adult Psychiatric Morbidity in England, 2007. Results of a Household Survey. The NHS Information Centre, 2010.

28 World Health Organization. World Report on Disability. World Health Organization, 2011.

29 Hiday VA, Swartz MS, Swanson JW, Borum R, Wagner HR. Criminal victimization of persons with severe mental illness. Psychiatr Serv 1999; 50: $62-8$.
30 Teasdale B. Mental disorder and violent victimization. Crim Justice Behav 2009; 36: 513-35.

31 Hiday VA, Swartz MS, Swanson JW, Borum R, Wagner HR, Hiday VA, et al. Impact of outpatient commitment on victimization of people with severe mental illness. Am J Psychiat 2002; 159: 1403-11.

32 Howard L, Trevillion $\mathrm{K}$, Khalifeh $\mathrm{H}$, Woodall A, Agnew-Davies R, Feder G. Domestic violence and severe psychiatric disorders: prevalence and interventions. Psychol Med 2010; 40: 881-93.

33 MIND. Another Assault: Mind's Campaign for Equal Access to Justice for People with Mental Health Problems. Mind, 2007.

34 Pettit B, Greenhead S, Khalifeh H, Drennan V, Hart T, Hogg J, et al. At Risk yet Dismissed: The Criminal Victimisation of People with Mental Health Problems. Victim Support, 2013.

35 Walby S, Allen J. Domestic Violence, Sexual Assault and Stalking: Findings from the British Crime Survey. Home Office, 2004.

36 Oram S, Trevillon K, Feder G, Howard LM. Prevalence of experiences of domestic violence among psychiatric patients: systematic review. Br J Psychiatry 2013; 202: 94-9.

37 Fisher HL, Craig TK, Fearon P, Morgan K, Dazzan P, Lappin J, et al. Reliability and comparability of psychosis patients' retrospective reports of childhood abuse. Schizophr Bull 2011; 37: 546-53.

38 Goodman LA, Thompson KM, Weinfurt K, Corl S, Acker P, Mueser KT, et al. Reliability of reports of violent victimization and posttraumatic stress disorder among men and women with serious mental illness. J Trauma Stress 1999; 12: 587-99.

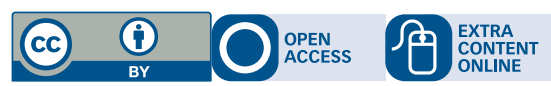

\section{0 (Potentially) traumatic events}

Ruth Reed

'Traumatic' events rip up the rule book of life. The ultimate impact depends not only on qualities of an event itself, but on its antecedents and consequences. Moreover, the meaning ascribed to the experience by the individual and the responses of friends, family and societal structures, determine whether the path that follows is one of guilt and shame or acceptance and recovery. Assumptions about others' experiences are often mistaken, being filtered through the imperfect lens of one's own internal world. Placing 'potentially' before 'traumatic' gives credence to the capacity for human growth and resilience, rising from the ashes of adversity. 